\title{
Neurogenin $3^{+}$cells contribute to $\beta$-cell neogenesis and proliferation in injured adult mouse pancreas
}

\author{
M Van de Casteele ${ }^{1,8}$, G Leuckx ${ }^{1,8}$, L Baeyens ${ }^{1}$, Y Cai ${ }^{1}$, Y Yuchi ${ }^{1}$, V Coppens ${ }^{1}$, S De Groef ${ }^{1}$, M Eriksson ${ }^{2}$, C Svensson ${ }^{2}$, U Ahlgren ${ }^{2}$, \\ J Ahnfelt-Rønne ${ }^{3}$, OD Madsen ${ }^{3}$, A Waisman ${ }^{4}$, Y Dor ${ }^{5,7}$, JN Jensen ${ }^{6}$ and H Heimberg ${ }^{1,7}$
}

We previously showed that injury by partial duct ligation (PDL) in adult mouse pancreas activates Neurogenin $3(\mathrm{Ngn} 3)^{+}$ progenitor cells that can differentiate to $\beta$ cells ex vivo. Here we evaluate the role of $\mathrm{Ngn}^{+}{ }^{+}$cells in $\beta$ cell expansion in situ. PDL not only induced doubling of the $\beta$ cell volume but also increased the total number of islets. $\beta$ cells proliferated without extended delay (the so-called 'refractory' period), their proliferation potential was highest in small islets, and $86 \%$ of the $\beta$ cell expansion was attributable to proliferation of pre-existing $\beta$ cells. At sufficiently high Ngn3 expression level, upto $14 \%$ of all $\beta$ cells and $40 \%$ of small islet $\beta$ cells derived from non- $\beta$ cells. Moreover, $\beta$ cell proliferation was blunted by a selective ablation of $\mathrm{Ngn}^{+}$cells but not by conditional knockout of $\mathrm{Ngn} 3$ in pre-existing $\beta$ cells supporting a key role for $\mathrm{Ngn}^{+}{ }^{+}$insulin ${ }^{-}$cells in $\beta$ cell proliferation and expansion. We conclude that $\mathrm{Ngn}^{+}$cell-dependent proliferation of pre-existing and newly-formed $\beta$ cells as well as reprogramming of non- $\beta$ cells contribute to in vivo $\beta$ cell expansion in the injured pancreas of adult mice.

Cell Death and Disease (2013) 4, e523; doi:10.1038/cddis.2013.52; published online 7 March 2013

Subject Category: Experimental Medicine

Adult non- $\beta$ cells do not form new $\beta$ cells during normal postnatal development or pregnancy, nor following partial pancreatectomy or partial $\beta$ cell ablation. ${ }^{1-3}$ Pre-existing $\beta$ cells are thus a major source of new $\beta$ cells under normal physiological conditions and following relatively mild injury in postnatal pancreas. ${ }^{1-3}$ The replication potential of these cells is homogeneous ${ }^{4}$ and limited by an extended delay or 'refractory period'. 3,5

We showed that severe injury caused by partial duct ligation (PDL) in adult mouse pancreas activates a population of embryonic-type endocrine progenitor cells. ${ }^{6}$ Expression of the earliest crucial transcription factor for embryogenesis of the endocrine pancreas, Neurogenin 3 (Ngn3), ${ }^{7-9}$ was strongly activated in PDL pancreas specifically in cells near the lining of ducts. ${ }^{6}$ These $\mathrm{Ngn}^{+}$cells did not derive from hormone ${ }^{+}$ cells and did not proliferate but, when isolated and grafted in explanted embryonic pancreas, differentiated towards functional $\beta$ cells with elevated cell cycle activity. ${ }^{6}$ Although insulin content and absolute $\beta$ cell mass increased in the ligated part of PDL pancreas ${ }^{6,10}$ it remains unclear whether adult $\mathrm{Ngn}^{+}$ non- $\beta$ cells contribute to $\beta$ cell formation in vivo. For instance, exocrine-to- $\beta$ cell transition in PDL pancreas has been confirmed by some ${ }^{11}$ but contradicted by other reports. ${ }^{12-15}$
The present study on $\beta$ cell dynamics in PDL pancreas by tracing of $\mathrm{Ngn}^{+}$cells, pre-existing $\beta$ cells, and on $\beta$ cell proliferation shows that $\beta$ cell neogenesis does occur in the PDL pancreas and that proliferation of both pre-existing and newly formed $\beta$ cells increases the $\beta$ cell volume in vivo.

\section{Results}

Partial duct ligation generated $\beta$ cell volume, new islets and $\boldsymbol{\beta}$ cells prone to redivide. PDL surgery caused doubling of $\beta$ cell mass in murine pancreas in some ${ }^{6,10}$ but not in other studies. ${ }^{12,15}$ Differences in tissue density between normal and duct ligated pancreas have been suggested to introduce a bias in $\beta$ cell mass measurements, ${ }^{12}$ therefore we determined $\beta$ cell volume in the ductligated part of pancreas (from hereon called PDL tail) as compared with Sham-operated control pancreas (Sham tail) of Balb-c mice. Throughout this study surgery was performed on male mice of 8 weeks. $\beta$ cell volume and islet size distribution were quantified by immunofluorescence in a semi-automated manner on $4 \mu \mathrm{m}$ thick sections, $36 \mu \mathrm{m}$ apart and spanning the whole tissue, corresponding to the analysis of $10 \%$ of the total volume of day 14 PDL- and Sham tail. The

\footnotetext{
${ }^{1}$ Diabetes Research Center, Vrije Universiteit Brussel, Brussels, Belgium; ${ }^{2}$ Umeå Centre for Molecular Medicine, Umeå University, Umeå, Sweden; ${ }^{3}$ Department of Islet Biology, Hagedorn Research Institute, Gentofte, Denmark; ${ }^{4}$ Institute for Molecular Medicine, University Medical Center of the Johannes Gutenberg-University of Mainz, Mainz, Germany; ${ }^{5}$ The Institute for Medical Research Israel-Canada, The Hebrew University, Jerusalem, Israel and ${ }^{6}$ Beta Cell Biology, Hagedorn Research Institute, Gentofte, Denmark

${ }^{*}$ Corresponding author: Dr H Heimberg, Diabetes Research Center,Vrije Universiteit Brussel, Laarbeeklaan 103, Brussels B1090, Belgium. Tel: + 322 4774477; Fax: + 322 4774472; E-mail: Harry.Heimberg@ vub.ac.be

${ }^{7}$ Members of the Center for Beta Cell Therapy in Diabetes, Brussels, Belgium.

${ }^{8}$ Shared first authorship.

Keywords: diabetes; cell differentiation; tissue injury

Abbreviations: bGal, beta galactosidase; CldU, 5-chloro-2'-deoxyuridine; Cre, Cre-recombinase; DT, diphtheria toxin; Cy, cyanine dye; FACS, fluorescence-activated cell sorting; iDTR, inducible simian diphtheria toxin receptor; IdU, 5-iodo-2'-deoxyuridine; Ins, insulin; i.v., intravenous; i.p., intraperitoneal; lacZ, beta galactosidase gene; $\mathrm{Ngn} 3$, neurogenin 3 gene; PDL, partial pancreatic duct ligation; R26, Rosa 26 locus; RIP, rat insulin promoter; RT-PCR, reverse transcription polymerase chain reaction; TAM, tamoxifen; TSQ, $\mathrm{Zn}^{2+}$-chelator 6-Methoxy-(8-p-toluenesulfonamido)quinoline; YFP, yellow fluorescent protein

Received 12.9.12; revised 19.1.13; accepted 29.1.13; Edited by M Federici
} 
total $\beta$ cell volume in PDL tail increased twofold as compared to Sham tail (Figure 1a). The total number of islets was increased more than twofold, specifically among the small $\beta$ cell clusters $\left(12-50 \mu \mathrm{m}\right.$ diameter; $\sim 1-10$ insulin $^{+}$cells on cross-section) (Figure 1b). Analysis of independent samples by automated whole-tissue optical projection tomography $(\mathrm{OPT})^{16-18}$ also indicated PDL-induced increase of total $\beta$ cell volume and islet number (Figure 1c).

To study the mechanism behind this $\beta$ cell expansion we first examined $\beta$ cell proliferation. From hereon, quantifications were done by inspection of individual cells, in a non-automated manner. In PDL tail the percentage of insulin $^{+}$cells containing the proliferation marker Ki67 was increased above the normal physiological level in Sham tail or in the unligated part of PDL pancreas (termed PDL head) (Figure 1d). The percentage of $\beta$ cells copositive for the $\beta$ cellspecific transcription factor Nkx6.1 and for Ki67 was likewise increased (Figure 1e) indicating elevated expression of Ki67 in $\beta$ cell nuclei. In mice that received the thymidine analog 5-iodo-2'-deoxyuridine (IdU) by intraperitoneal (i.p.) injection 8
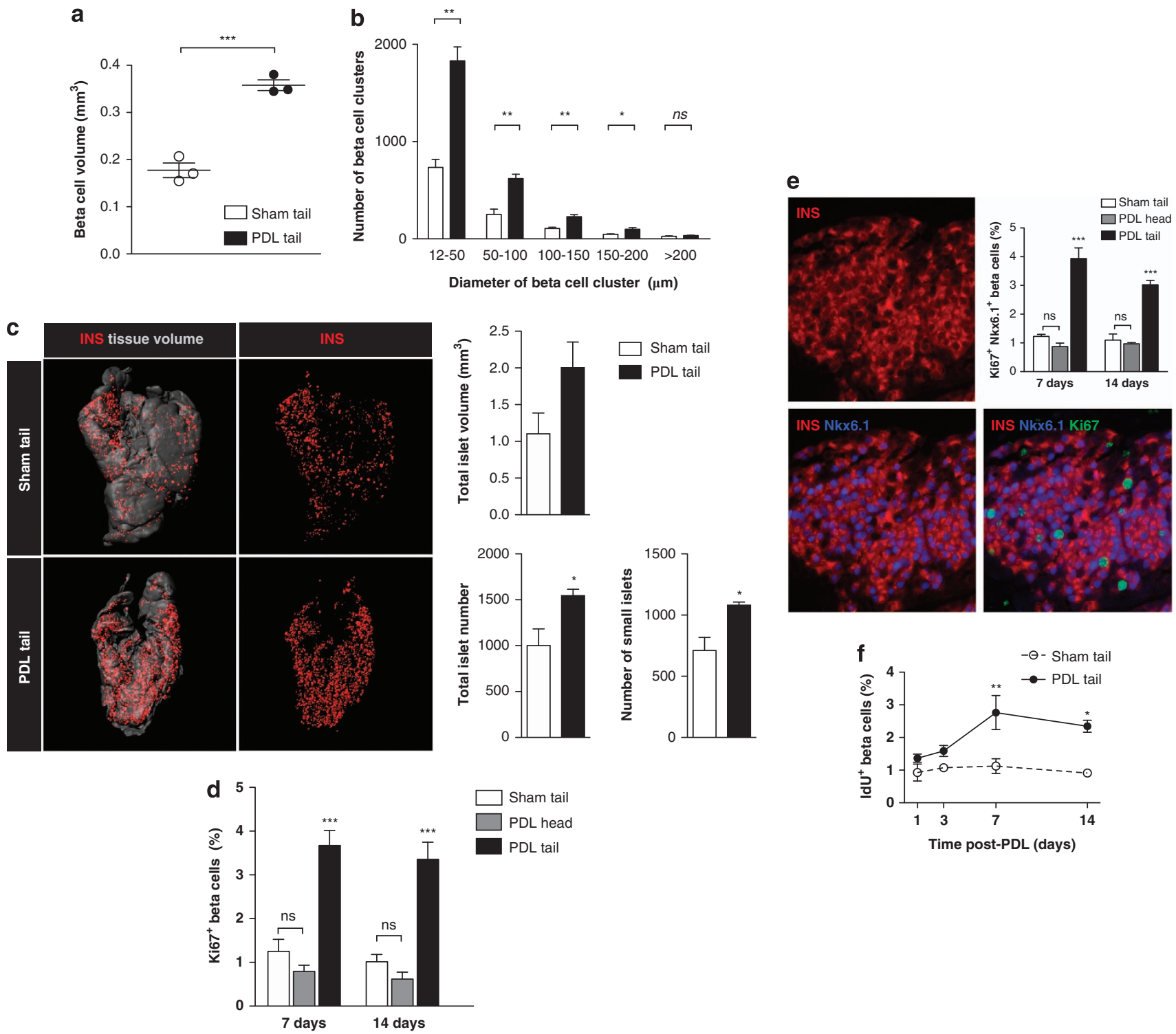

Figure $1 \mathrm{PDL}$ induces islet formation and $\beta$ cell proliferation in adult mouse pancreas. Eight-week-old male Balb-c mice, underwent PDL or Sham surgery. (a) PDL and Sham tail total $\beta$ cell volume $\left(\mathrm{mm}^{3}\right)$ and $(\mathbf{b})$ number of $\beta$ cell clusters in the indicated diameter $(\mu \mathrm{m})$ categories $\left(n=3 ;{ }^{*} P<0.05,{ }^{\star \star} P<0.01,{ }^{* \star \star} P<0.001, \mathrm{~ns}: P>0.05, \mathrm{PDL}\right.$ versus Sham tail). (c) Panels show the total tissue volume (gray) and insulin ${ }^{+}$volumes (red) detected by OPT microscopy in tail regions of Sham or PDL operated pancreases. The total islet volume increased after PDL to $2.0 \times 10^{9} \pm 3.5 \times 10^{8} \mu \mathrm{m}^{3}$ (compared with Sham tail $1.1 \times 10^{9} \pm 2.8 \times 10^{8} \mu \mathrm{m}^{3} ; n=3 ; P=0.056$ ). The total number of insulin ${ }^{+}$islets significantly increased from $1000 \pm 184$ in Sham to $1539 \pm 77$ in PDL tails $(n=3 ; P<0.05)$. This increase could be attributed to a significant increase in small islets $\left(<10^{6} \mu \mathrm{m}^{3}\right)(711 \pm 107$ islets in Sham versus $1082 \pm 25$ islets in PDL; $n=3 ; P<0.05)$. (d,e) $\beta$ cell proliferation was determined in ligated PDL tail, unligated PDL head or Sham tail pancreas, at 7 and 14 days post-PDL by immunofluorescence staining (d) for insulin and Ki67 ( $n=5-14)$ or (e) for insulin, Nkx6.1 and Ki67 ( $n=3)$ ( ${ }^{* \star \star} P<0.001$, ns: $P>0.05$, versus Sham tail or PDL head by two-way ANOVA). (f) 5 -iodo-2'-deoxyuridine (IdU, $1 \mathrm{mg} / \mathrm{ml}$ ) was i.p. injected precisely at 8 and $4 \mathrm{~h}$ before sacrifice at the indicated time points following PDL. The percentage of IdU-labeled $\beta$ cells was determined by immunostaining for insulin and IdU $\left(n=3,{ }^{*} P<0.05,{ }^{* *} P<0.01\right.$ versus Sham tail by two-way ANOVA). $1800 \pm 200 \beta$ cells were counted per tissue sample. See also Supplementary Figure S4A 
and $4 \mathrm{~h}$ before sacrifice, $\beta$ cell labeling was significantly higher in PDL tail than in Sham tail at days 7 and 14 following surgery (Figure 1f).

In (re)generation models studied so far very few $\beta$ cells go through multiple cell cycles. ${ }^{3}$ Labeling mice first with the thymidine analog 5-chloro-2'-deoxyuridine (CldU) and then with IdU allows tracing cells that have undergone one or more rounds of division in vivo. ${ }^{3}$ To minimize the risk of misinterpretation of data we used the published antibodies for specific detection of either CldU or $\mathrm{IdU},{ }^{3}$ verified whether these antisera reacted specifically with either analog in PDL pancreas and found no cross-reactivity (Supplementary Figures S1A and B). Second, CldU- and IdU-labeled cells were detected using fluorescent probes Cy5 and Cy2, respectively, which have minimal overlap in excitation/emission spectra (Supplementary Figures S1C and D).

As control experiment, double labeling of $\beta$ cells was evaluated in neonatal Balb-c mice that received i.p. CldU on day 5 (P5) and i.p. IdU on P6. This resulted in high numbers of CldU-single positive and IdU-single positive $\beta$ cells, but only very few doubly labeled $\beta$ cells (Figure $2 \mathrm{a}$ and Supplementary Figure S2A). These data closely match the (re)-replication rates for neonatal $\beta$ cells previously published by others ${ }^{3}$ and support their general conclusion that $\beta$ cells are virtually always labeled with CldU or IdU, but rarely both. ${ }^{3} \mathrm{PDL}$ surgery was immediately followed by administration of CldU and IdU via the drinking water (Figures $2 b-d$ ). At the end of the labeling period a considerable fraction of the $\beta$ cells had re-replicated as indicated by $\mathrm{CldU}^{+} \mathrm{IdU}^{+}$double labeling (Figures $2 \mathrm{~b}-\mathrm{d}$ and Supplementary Figures S2B-D). Following 7 days CldU and 7 days IdU labeling, $4.3 \pm 0.5 \%$ of $\beta$ cells (5500 insulin ${ }^{+}$ cells counted in duct-ligated pancreas of five mice) were doubly labeled (Figure $2 \mathrm{c}$ ) compared with the $\leq 1.5 \%$ reported for neonatal (Figures $2 a$ and 3 ), pregnant or pancreatectomized mice. ${ }^{3}$ Quantification of CldU ${ }^{+}$IdU $^{+} \beta$ cells by confocal microscopy on another set of PDL samples with 7 days CldU and 7 days IdU labeling (Supplementary Figure S3) corroborated the data obtained by fluorescence microscopy (Figure 2c). The likelihood of re-replication for $\beta$ cells in PDL

Figure $2 \beta$ cells of PDL pancreas redivide without extended delay ('refractory period $)$. Insulin ${ }^{+} \beta$ cells were scored for CldU and/or IdU labeling using analogspecific antibodies. By labeling a first cell division with CldU (blue) and a second one with IdU (green), sequential divisions result in colabeled $\beta$ cells (blue and green). (a) Neonatal Balb-c mice received i.p. CldU on day 5 (P5), and i.p. IdU on postnatal day 6 (P6), and were sacrificed $24 \mathrm{~h}$ later. P6 mice pancreas displayed high percentages of CldU-single positive (blue nuclei) and IdU-single positive (green nuclei) $\beta$ cells (red) but only very few double-labeled $\mathrm{CldU}^{+} \mathrm{IdU}^{+} \beta$ cells (blue and green nuclei). $\left(n=6,7316\right.$ insulin ${ }^{+}$cells evaluated). Eight-week-old male Balb-c mice underwent PDL surgery and CldU and IdU were sequentially administered via the drinking water: (b) 3 days CldU +3 days IdU ( $n=6,8172 \beta$ cells counted), (c) 7 days CldU +7 days IdU ( $n=5,5505 \beta$ cells counted), (d) 7 days CldU +28 days IdU $(n=3,5816 \beta$ cells counted). (e) On the basis of the data obtained in $(\mathbf{a}-\mathbf{d})$, the likelihood of redivision of $\beta$ cells was calculated (see formula) and plotted versus duration of the cognate IdU labeling period, fitting the modeled exponential function $f(x)=\left(1-a^{x-r}\right) /\left(1-a^{x}\right)$, where $\mathbf{x}=$ days of IdU labeling, $a=$ probability of non-labeling per day and $\mathbf{r}=$ refractory period in days. The curve fitted the experimental PDL data (b-d), as well as data obtained by ${ }^{3}$ for partial pancreatectomy (PPx), pregnant mice (Preg), neonatal mice (Neo), or non-treated mice (non-treated). For comparison, our data on neonatal mice (a) are also represented by a datapoint ${ }^{*}$ ) in (e). See also Supplementary Figures S2 and S3. Scale bars represent $50 \mu \mathrm{m}$ tail was $>100 \%$ for each of the labeling protocols (Figure $2 e$, data points of Figures $2 \mathrm{~b}-\mathrm{d}$ ) in contrast to $\beta$ cell proliferation in neonatal mice (Figure $2 \mathrm{e}$, data point of Figure $2 \mathrm{a}$ ) and other models (Figure 2e). This indicated that part of the $\beta$ cells in PDL tail redivided more often than theoretically expected from stochastic kinetics, representing a subpopulation of $\beta$ cells in PDL tail that preferentially cycle.
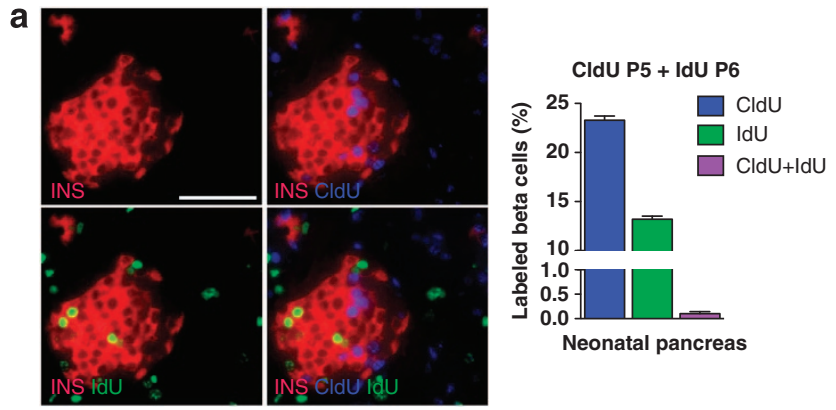

b

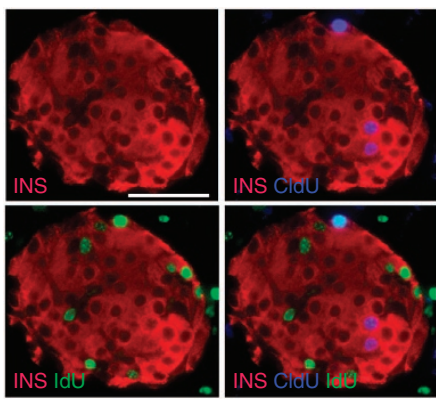

$3 d$ CIdU + 3d IdU

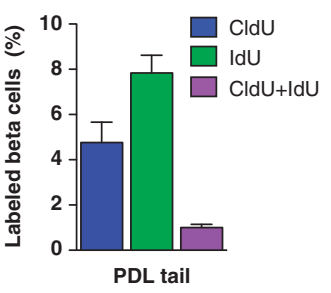

C
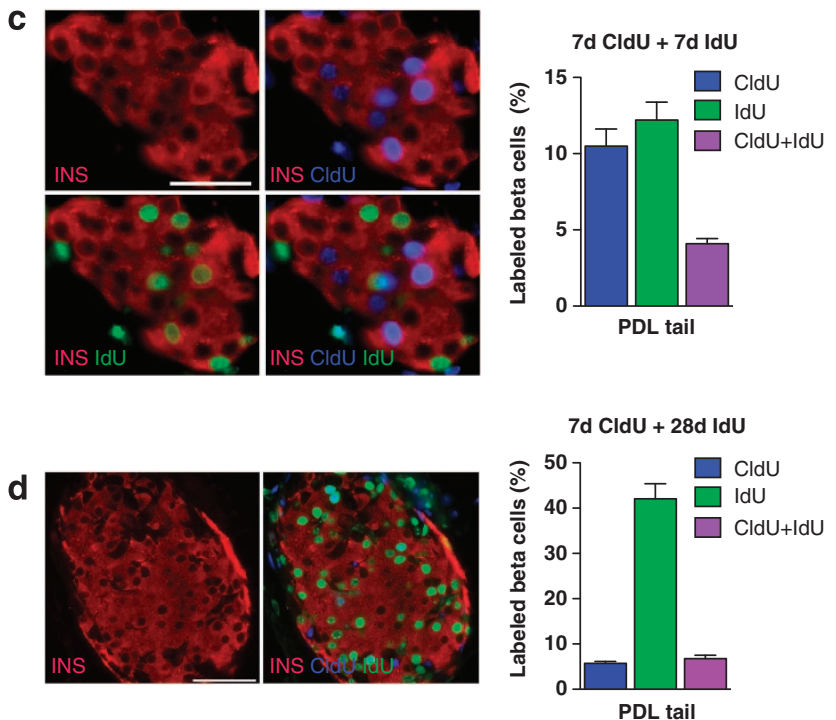

e

Likelihood of redivision $=$

$100 \% \times\left(\right.$ Fraction $\mathrm{CldU}^{+} \mathrm{IdU}^{+}$)

$\left(\right.$ Fraction $\left.\mathrm{CldU}^{+}\right) \times\left(\right.$Fraction $\left.\mathrm{IdU}^{+}\right)$

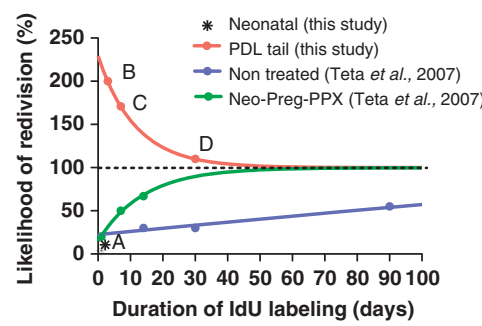


Continuous thymidine analog labeling during 7, 14 or 35 days showed long-term subsistence of a higher proliferation potential by $\beta$ cells in small clusters of $1-20$ insulin ${ }^{+}$cells in PDL tail (Figures $3 a-c$, respectively). At 35 days post-PDL the majority of clusters with $\leq 20$ insulin $^{+}$cells consisted entirely of insulin $^{+}$cells that had divided (Figure 3d), indicating that the majority of small islets are generated through replication. In addition, consecutive labeling with CldU and IdU showed that the rate of redivision by $\beta$ cells in PDL tail was highest in small clusters (Figure $3 e$ ). IdU pulse labeling indicated different proliferation kinetics in small and large (21-200 insulin ${ }^{+}$cells) clusters of PDL tail, but no changes in the corresponding $\beta$ cell populations of Sham tail (Figure $3 f$ ). These results assign small islets as the preferential site for $\beta$ cell (re)division. On the basis of the IdU pulse label and volumetric assay of $\beta$ cells in PDL and Sham tail pancreas, the $\beta$ cell growth was mathematically modeled. The calculations suggested that proliferation of pre-existing $\beta$ cells can account for $86 \%$ of the $\beta$ cell expansion observed in PDL tail (Supplementary Figure S4A) and that small clusters present at day 7 of PDL can expand their $\beta$ cell numbers nearly threefold in the second week of PDL to generate larger clusters (Supplementary Figure S4B).
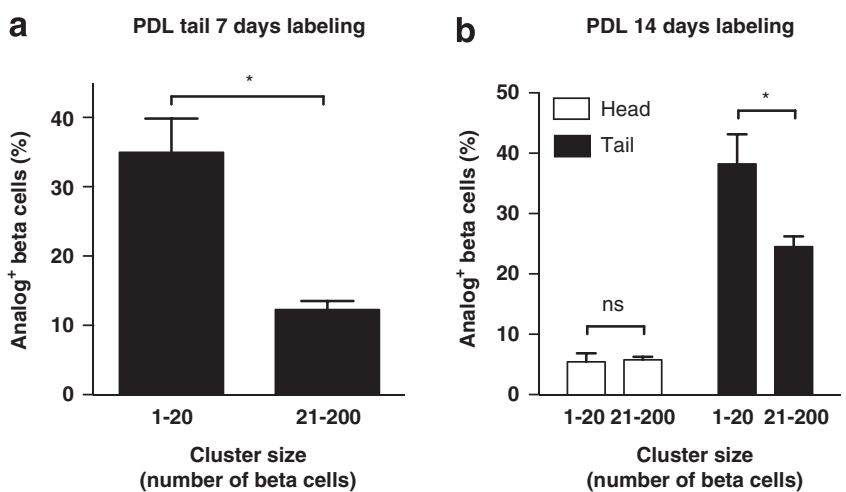

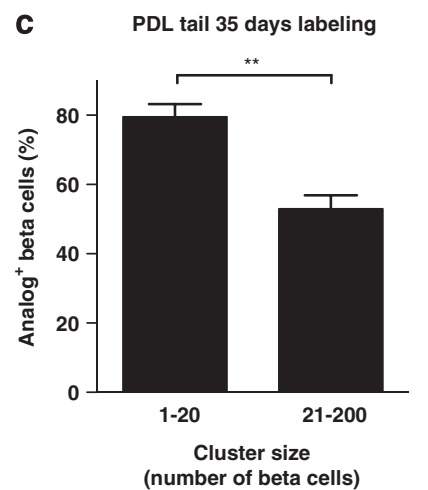

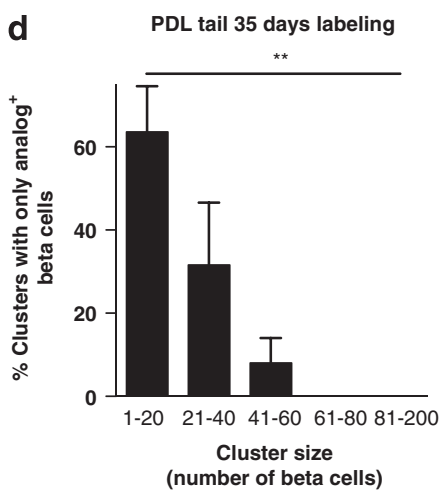
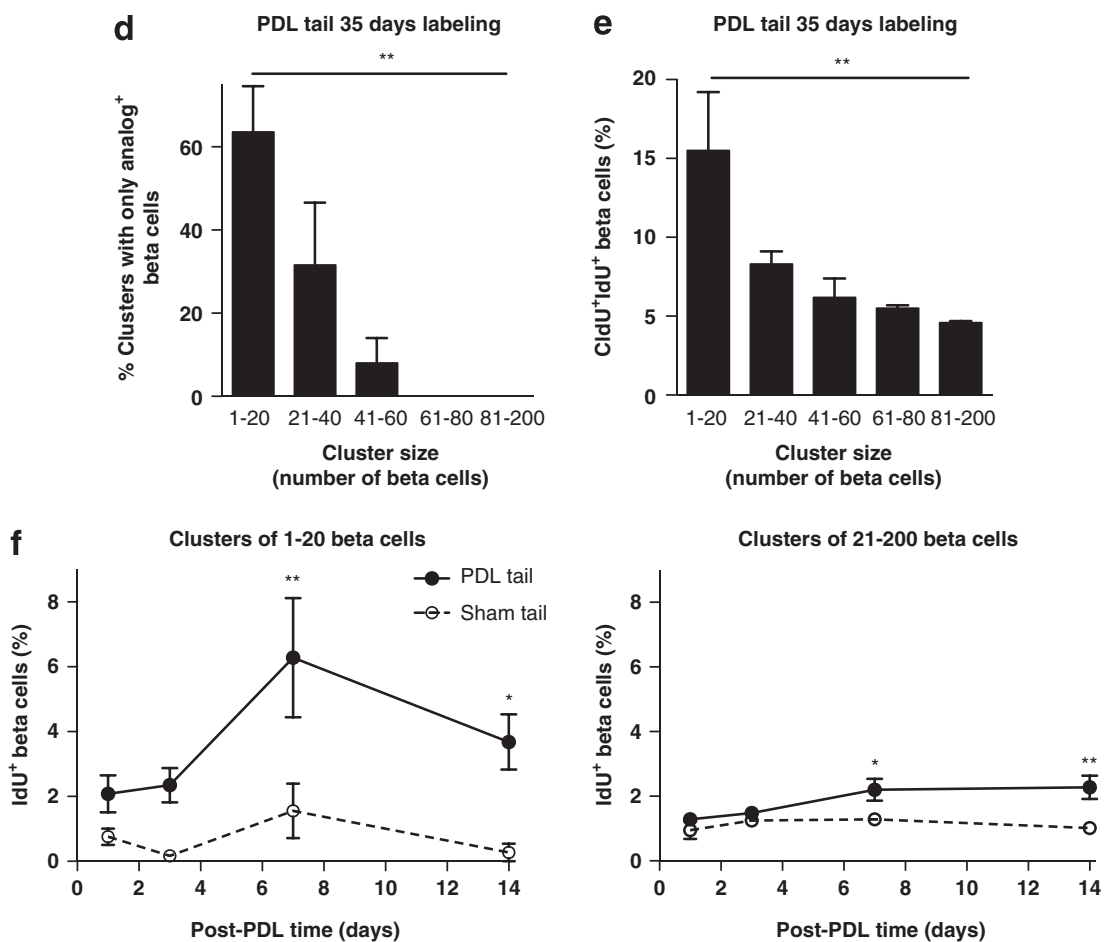

Figure 3 Small $\beta$ cell clusters are the preferred site of $\beta$ cell (re)division in PDL pancreas. Eight-week-old male Balb-c mice underwent PDL surgery and were continuously labeled with thymidine analogs via the drinking water. Proliferation was analyzed by immunofluorescence staining for either IdU or IdU and CldU in insulin ${ }^{+}$cells. Small clusters were defined as clusters of 1-20 $\beta$ cells on cross-section while large clusters contained 21-200 $\beta$ cells. Data are expressed as mean \pm S.E.M. of the percentage of $\beta$ cells that were positive for thymidine analog in each size category. (a) Seven days IdU-labeling of $\beta$ cells in PDL tail $\left(n=5,{ }^{* *} P<0.005\right)$, (b) 14 days IdU-labeling of $\beta$ cells in PDL head and tail $\left(n=4-7,{ }^{*} P<0.02\right.$, ns: $\left.P>0.05\right)$. (c) Thirty-five days of IdU-labeling of $\beta$ cells in the PDL tail $\left(n=3,{ }^{*} P<0.01\right)$. (d) Data from (c) analyzed for subcategories of clusters, and expressed as the percentage of clusters consisting of only analog ${ }^{+} \beta$ cells. Clusters comprising $>60$ insulin ${ }^{+}$cells never consisted entirely of analog ${ }^{+} \beta$ cells. $\left(n=3,{ }^{* *} P<0.01\right.$ by one-way Anova) (e) 7 days CldU labeling followed by 28 days IdU labeling and evaluation of the percentage of CldU ${ }^{+}$IdU ${ }^{+}$labeled (redivided) $\beta$ cells according to cluster size ( $n=3,{ }^{* *} P<0.01$ by one-way Anova). (f) $8 \mathrm{~h}$ IdU pulse labeling of $\beta$ cells in small and large clusters of PDL and Sham tail pancreas $\left(n=3 ;{ }^{*} P<0.05,{ }^{*} P<0.01\right.$ versus same time point for Sham tail, by 2 -way Anova). See also Supplementary Figure S4B 
a

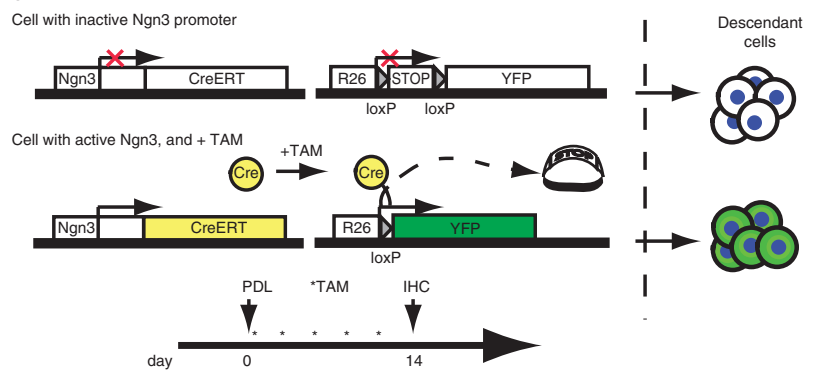

d

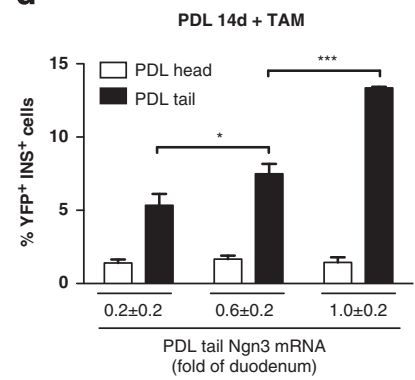

b
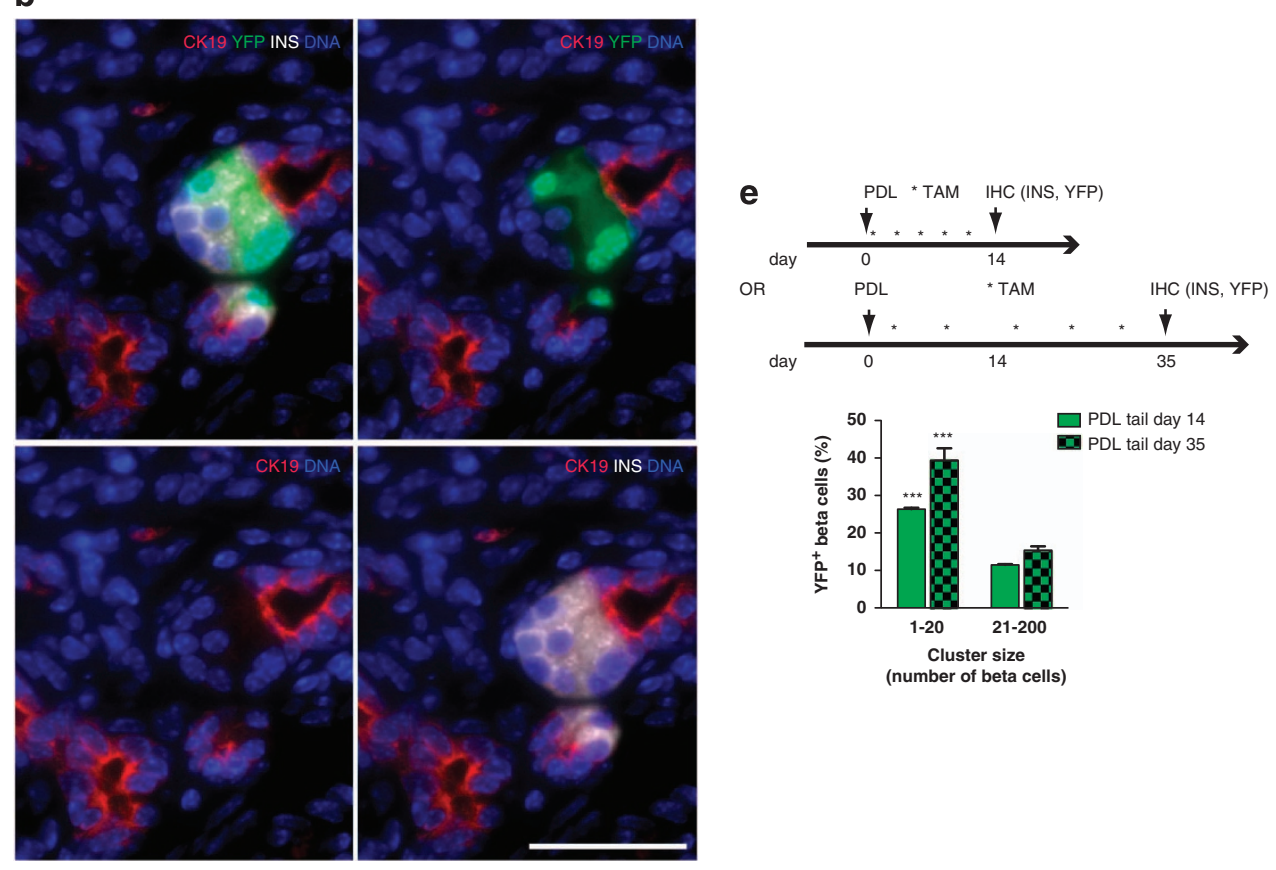

C
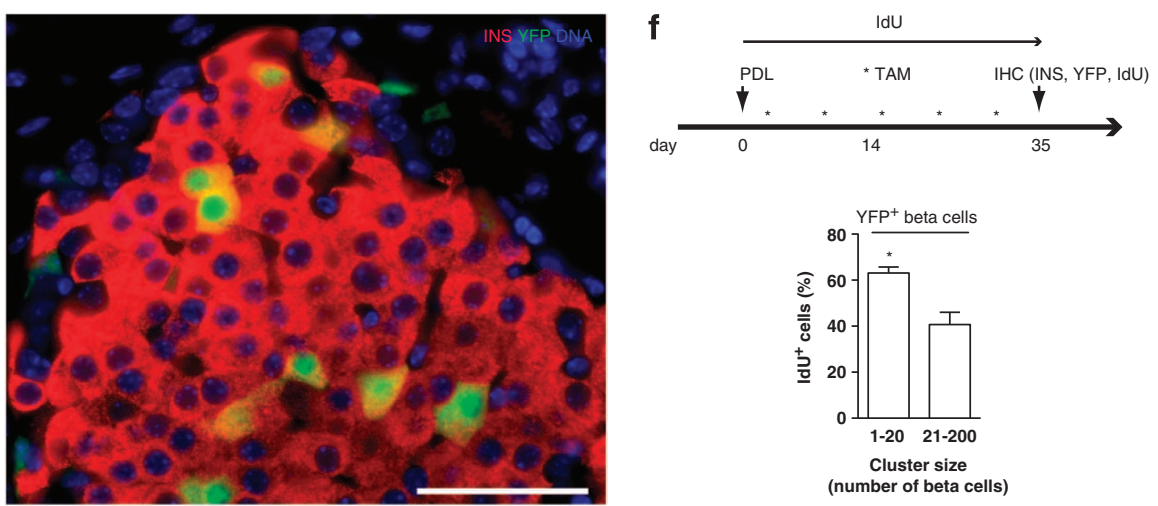

Figure $4 \beta$ cells derived from $\mathrm{Ngn}^{+}$cells preferentially locate and proliferate in small $\beta$ cell clusters of PDL pancreas. (a) Description of the transgenic mouse model and the labeling strategy for heritable tracing of Ngn3 expressing cells. Ngn3 = Ngn3 gene promoter, R26 = Rosa26 locus, loxP = loxP sequence, STOP = transcriptional STOP sequence, YFP = yellow fluorescent protein. Tamoxifen injection (TAM, ${ }^{*} 4 \mathrm{mg} /$ injection) of bigenic Ngn3 ${ }^{\mathrm{CreERT}}$; R26 ${ }^{\mathrm{YFP}}$ mice results in Cre-mediated removal of the lox-P flanked STOP sequence, and permanent expression of the YFP reporter gene in cells with an active Ngn3 promoter and their descendants. Eight-week-old male bigenic mice underwent PDL surgery and were TAM-injected (s.c., starting on day of surgery: 4 mg TAM, repeated once every-other-day, five injections in total). (b) YFP-staining in small clusters of Insulin ${ }^{+} \mathrm{CK} 19^{+}$cells associated with CK19 ${ }^{+}$duct cells of PDL tail. (c) YFP ${ }^{+}$INS ${ }^{+} \beta$ cells in islets of PDL tail. (d) Quantification of the percentage YFP ${ }^{+} \beta$ cells in PDL head and tail with the indicated range of Ngn3 mRNA expression level in PDL tail 14 days after ligation $\left(n=3,{ }^{*} P<0.05,{ }^{* *} P<0.01\right.$ by two-way ANOVA; a total of $21295 \beta$ cells evaluated). Ngn3 mRNA was expressed relative to cyclophilin A mRNA and normalized to Ngn3 expression in duodenum. (e) Quantification of the percentage of YFP $^{+} \beta$ cells in small (1-20 insulin ${ }^{+}$cells) and large (21-200 insulin ${ }^{+}$cells) clusters in PDL tail day 14 and 35 (three mice per experimental condition, ${ }^{* * *} P<0.001$ versus large clusters, by two-way ANOVA). (f) Quantification of percentage IdU-labeling (proliferation) in YFP ${ }^{+} \beta$ cells in small and large clusters $\left(n=3,{ }^{*} P<0.05\right.$, versus large clusters). (See also Supplementary Figure S5). Scale bars represent $50 \mu \mathrm{m}$ 
$\beta$ cells derived from $\mathrm{Ngn}^{+}$cells locate preferentially in small islets and proliferate. $\mathrm{Ngn}^{\mathrm{CreERT}} ; \mathrm{R}^{\mathrm{C}} \mathrm{C}^{\mathrm{YFP}}$ mice $^{19,20}$ were generated to evaluate possible contribution of progenitors to $\beta$ cell growth by permanent tracing of cells with activated Ngn3 and descendants thereof. These cells constitutively express the reporter protein YFP once the stop sequence that prevents reporter gene expression is removed (Figure 4a) upon treatment of mice with tamoxifen (TAM). Male Ngn3 ${ }^{\text {CreER- }}$ T;R26YFP mice of 8 weeks underwent PDL surgery, were subcutaneously injected with TAM and were sacrificed at day 14 post-PDL (Figure 4a). As Ngn3 progenitors could be activated at any time-point following PDL and the Ngn3 promoter activity in these cells is transient, ${ }^{6,9}$ repeated injections of tamoxifen were applied (starting at the day of surgery: s.c. injection of $4 \mathrm{mg}$, repeated once-every-other-day, five injections in total) for maximizing the number of labeled progenitors (Figure 4a). YFP was expressed in enteroendocrine cells of duodenum (Supplementary Figure S5A), in cytokeratin19 ${ }^{+}\left(\mathrm{CK}_{19}{ }^{+}\right)$and insulin ${ }^{+}\left(\mathrm{INS}^{+}\right)$cells located along the duct lining (Supplementary Figures S5B and C), and in small clusters of $\mathrm{CK} 19^{+} \mathrm{INS}^{+}$cells associated with ducts (Figure 4b). The fraction of $\mathrm{YFP}^{+} \beta$ cells in islets (Figure 4c, Supplementary Figure $\mathrm{S} 5 \mathrm{D}$ ) increased with $\mathrm{Ngn} 3$ transcript level in PDL tail but not in PDL head (Figure 4d). These results suggest that the contribution of $\mathrm{Ngn}^{+}$cells to $\beta$-cell neogenesis correlates to the level of Ngn3 gene expression following injury. In PDL tails with a Ngn3 transcript level above $60 \%$ of duodenum, $39.4 \pm 3.2 \%$ of $\beta$ cells were $\mathrm{YFP}^{+}$in small versus $15.4 \pm 1.1 \%$ in large clusters, at day 35 post-PDL (Figure 4e). In PDL head, no such difference was found $(0.6 \pm 0.6 \%$ YFP labeling of $\beta$ cells in small clusters versus $1.49 \pm 0.16 \%$ in large clusters, $P>0.05, n=9$ ). Labeling mice with the thymidine analog IdU via the drinking water indicated that a large fraction of $\mathrm{YFP}^{+} \beta$ cells in PDL tail pancreas was involved in proliferation and that $\mathrm{YFP}^{+}$insulin $^{+}$cells proliferated more in small than in large $\beta$ cell clusters (Figure 4f).

New $\beta$ cells dilute pre-existing $\beta$ cells in PDL islets. To investigate whether in PDL pancreas $\beta$ cells can also derive from non- $\beta$ cells, the ratio between pre-existing and newly formed $\beta$ cells was investigated in RIP ${ }^{\text {CreERT }} ;$ R26 $^{\text {LacZ }}$ mice $^{1}$ (Figure 5a). Following TAM-treatment, washout and PDL surgery, mice were sacrificed after a 14 or 35 days chase period (Figure 5a). PDL tails with high Ngn3 mRNA (>60\% of duodenum transcript level) were analyzed for the presence of $\mathrm{bGal}^{+} \beta$ cells and compared with PDL head of the same pancreas. In PDL head $82 \pm 5 \%$ of $\beta$ cells $\left(6720\right.$ INS $^{+}$cells counted in three mice) expressed bGal, representing the labeling efficiency at day 14 post-PDL (Figure 5b). In PDL tail of the same mice, $74 \pm 6 \%$ of all $\beta$ cells $\left(8216\right.$ insulin $^{+}$cells counted) was bGal ${ }^{+}$(Figure 5b). During 14 days following surgery pre-existing $\beta$ cells had been diluted by unlabeled newly formed $\beta$ cells in small islets of PDL tail only (Figure $5 b$ ). An extended post-PDL chase period of 35 days resulted in a statistically significant decrease ( $70 \pm 4 \%$ versus $82.5 \pm 0.3 \%)$ in preponderance of $\mathrm{bGal}^{+} \beta$ cells in PDL tail (14510 INS ${ }^{+}$ cells counted in three mice) as compared with PDL head (13544 INS $^{+}$cells counted) (Figure 5c). The dilution of labeled cells indicated that up to $14.6 \%$ of all $\beta$ cells and $42 \%$ of $\beta$ cells in small islets in PDL tail derived from non- $\beta$ cells (Supplementary Figure S4C). The preponderance of $\mathrm{bGal}^{+}$ $\beta$ cells at day 35 was significantly decreased in islets of various sizes in PDL tail (Figure $5 \mathrm{c}$ ). Remarkable were islets that consisted nearly entirely of bGal ${ }^{-}$insulin $^{+}$cells (Figure $5 \mathrm{~d}$, Supplementary Figure S6) whereas bGal $^{+}$insulin $^{+}$cells predominated in islets of PDL head of the same mice (Figure 5e, Supplementary Figure S6). With an average of $70 \%$ bGal $^{+} \beta$ cells in PDL tail (Figure $5 \mathrm{c}$ ), binomial probability calculation results in a chance of $5.4 \times 10^{-7}$ for any islet with $20 \beta$ cells of having only three or less bGal ${ }^{+} \beta$ cells. In reality, 12 out of 186 islets with $20-200 \beta$ cells $\left(=6.4 \times 10^{-2}\right)$ were found with three or less $\mathrm{bGal}^{+} \beta$ cells in PDL tail. In PDL head of these mice, no such islets were observed (276 large islets inspected). This finding excludes that these islets with strongly diluted label arose by chance. Similar results were obtained in independent experiments using RIPCreERT;R26 $6^{\text {YFP }}$ mice $^{20,21}$ (Supplementary Figure S7). The active dilution of pre-existing labeled $\beta$ cells in PDL tail supports a process of $\beta$ cell neogenesis from non- $\beta$ cells.

$\mathrm{Ngn}^{+}$non- $\beta$ cells are required for $\beta$ cell formation in PDL pancreas. Above results suggested that expansion of the $\beta$ cell mass in PDL pancreas correlates with activation of Ngn3 gene expression and occurs by proliferation of both preexisting and newly formed $\beta$ cells. To address the role of $\mathrm{Ngn}^{+}$cells in $\beta$ cell expansion, the effect of their selective ablation was studied. $\mathrm{Ngn}^{\mathrm{CreERT}} ; \mathrm{R} 26^{\text {iDTR }}$ mice were generated to constitutively express simian diphtheria toxin receptor (DTR) following removal of a transcriptional STOP cassette ${ }^{22}$ by inducible CreERT recombinase whose expression is controlled by the Ngn3 promoter. ${ }^{19}$ Administration of diphtheria toxin (DT) to R26 $6^{\mathrm{iDTR}+1+}$ mice specifically and efficiently kills cells that have undergone Cre-mediated deletion of the STOP sequence. ${ }^{22} \mathrm{PDL}$ surgery and TAM administration to $\mathrm{Ngn}^{\mathrm{CreERT}-1+} ; \mathrm{R}^{\mathrm{B}} 6^{\mathrm{iDTR}+1+}$ mice or $\mathrm{Ngn3}^{\mathrm{CreERT}-1-}$ ;R26 $6^{\text {ITR }+1+}$ control littermates was followed by i.v. injection of DT (Figure 6a). On the basis of the Ngn3 transcript level, $77 \%$ of $\mathrm{Ngn}^{+}$enteroendocrine progenitor cells in duodenum and $66 \%$ of $\mathrm{Ngn}^{+}$cells in PDL tail could be ablated (Figure $6 \mathrm{~b}$ ), resulting in $28 \%$ decrease in insulin content (Figure 6c). In

\footnotetext{
Figure 5 New $\beta$ cells can derive from non- $\beta$ cells in PDL pancreas. (a) Description of the transgenic mouse and the strategy for labeling and tracing pre-existing $\beta$ cells (legend as in Figure 4). Tamoxifen s.c. injection ( ${ }^{*} \mathrm{TAM}, 4 \mathrm{mg} /$ injection) of bigenic RIPCre ERT; R2 $6^{\text {lacZ }}$ mice of 8 weeks results in transient nuclear translocation of CreERT, leading to removal of the loxP-flanked STOP sequence and permanent heritable expression of the lacZ reporter gene (encoding $\beta$ galactosidase, bGal) in $\beta$ cells. A 14 days TAM-washout (WO) period assured the absence of residual TAM at the time of surgery. PDL-surgery was followed by a label-chase period of 14 or 35 days after which islets in PDL head or PDL tail were examined by immunostaining for bGal expression in insulin ${ }^{+}$cells. Non $\beta$ cell-derived $\beta$ cells would dilute the label and decrease the preponderance of bGal ${ }^{+}$insulin ${ }^{+}$cells. (b) bGal expression in insulin ${ }^{+}$cells following 14 or (c) 35 -days chase period. Left panels, preponderance of bGal ${ }^{+}$insulin ${ }^{+}$cells; right panels, preponderance of $\mathrm{bGal}^{+}$insulin ${ }^{+}$cells in clusters of different sizes. Data are expressed as the mean \pm S.E.M. obtained with three mice $\left({ }^{*} P<0.05,{ }^{* *} P<0.01\right)$. (d) Immunofluorescent staining for detection of pre-existing $\left(\mathrm{bGal}^{+}{ }^{\text {insulin }}{ }^{+}\right.$) $\beta$ cells in PDL tail and (e) in PDL head, after 35 days chase period. (See also Supplementary Figures S4C,S6 and S7). Scale bars represent $50 \mu \mathrm{m}$
} 
contrast, DT treatment did not affect the insulin content in PDL head (Figure $6 \mathrm{c}$ ). Ablation of $\mathrm{Ngn}^{+}$cells reduced $\beta$ cell proliferation by $53 \%$ in PDL tail, while in PDL head no effect on $\beta$ cell proliferation was observed (Figure $6 \mathrm{~d}$ ). These data suggests that both the insulin content and the $\beta$ cell proliferation partially depend on $\mathrm{Ngn}^{+}$cells in PDL tail. Strikingly, in small

a

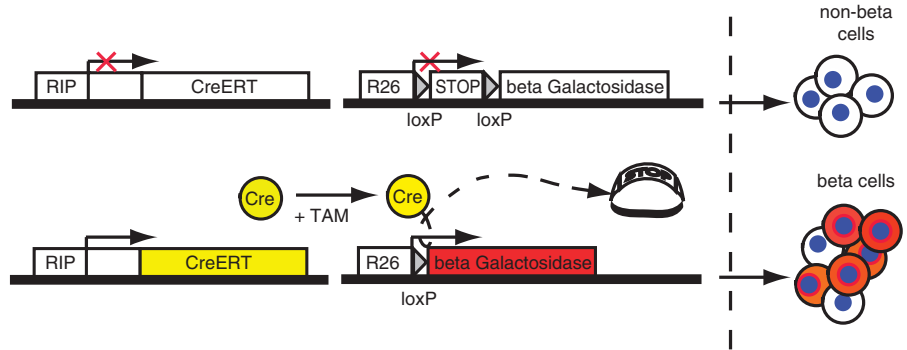

day
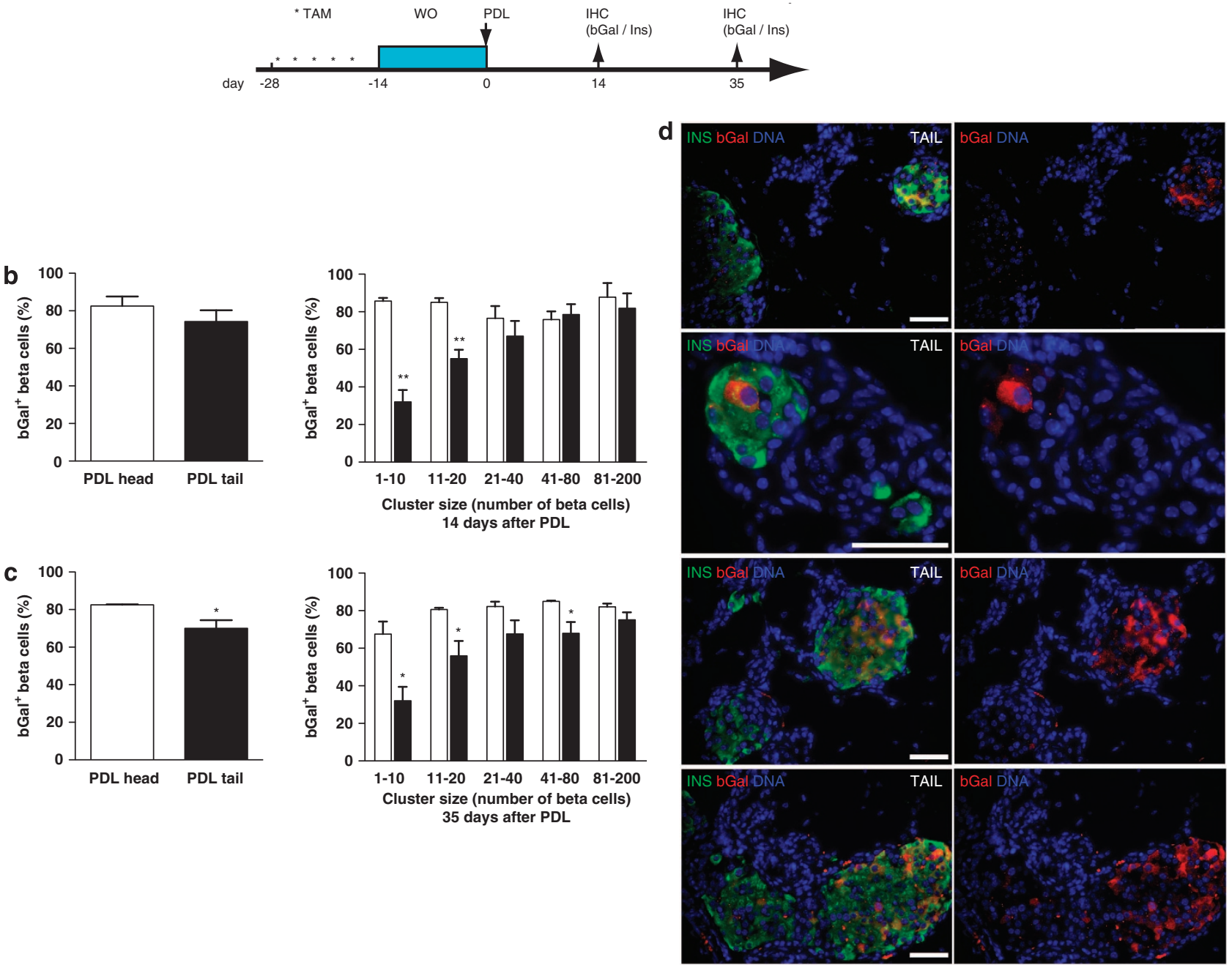

35 days after $P D L$

e
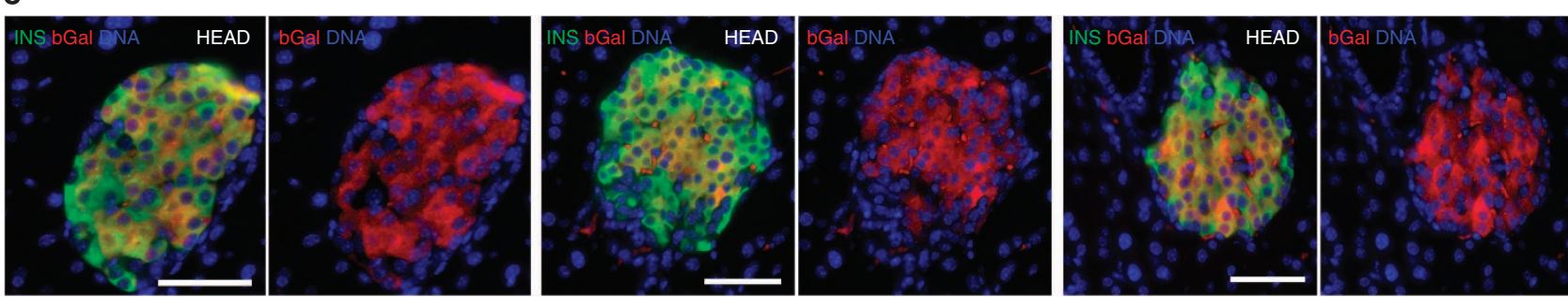
clusters of $1-20 \beta$ cells, $\beta$ cell proliferation was reduced by $66 \%$ (Figure 6e), suggesting complete dependence on $\mathrm{Ngn}^{+}$cells. DT treatment of $\mathrm{Ngn}^{\mathrm{CreERT}-/+} ; \mathrm{R}^{\mathrm{i} 6^{\mathrm{iDTR}+/+}}{ }^{\text {, Sham operated }}$ mice showed no effect on insulin content, nor on $\beta$ cell proliferation (Supplementary Figure S8). Together the results indicate that $\mathrm{Ngn}^{+}$cells are required for the expansion of $\beta$ cells in PDL pancreas, while in normal pancreas $\mathrm{Ngn}^{+}$cells do not contribute to the generation of $\beta$ cells. a

Cell with inactive Ngn3 promoter

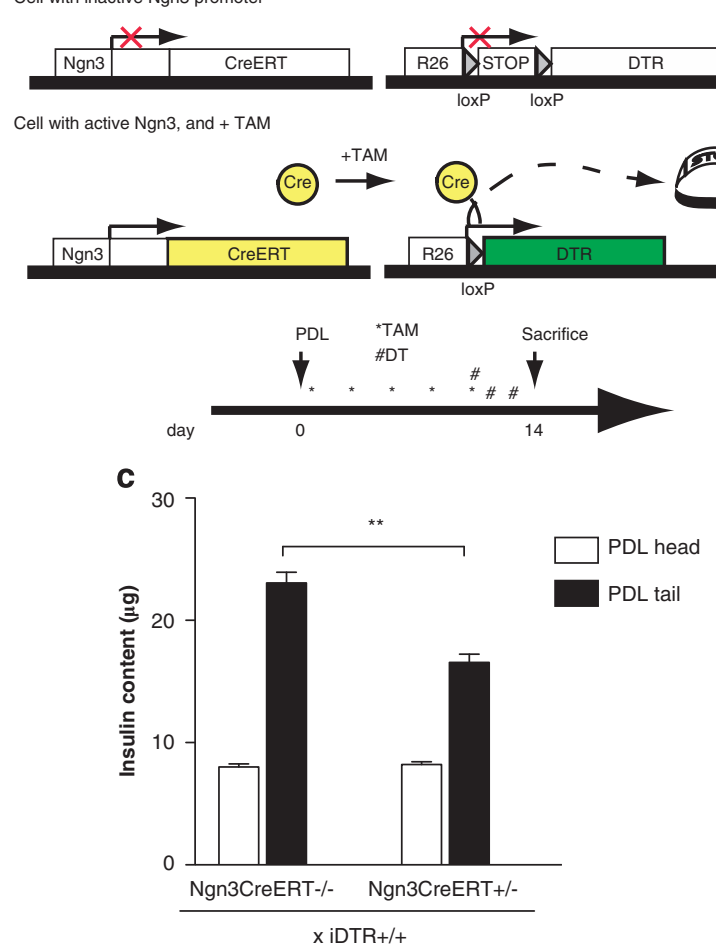

e

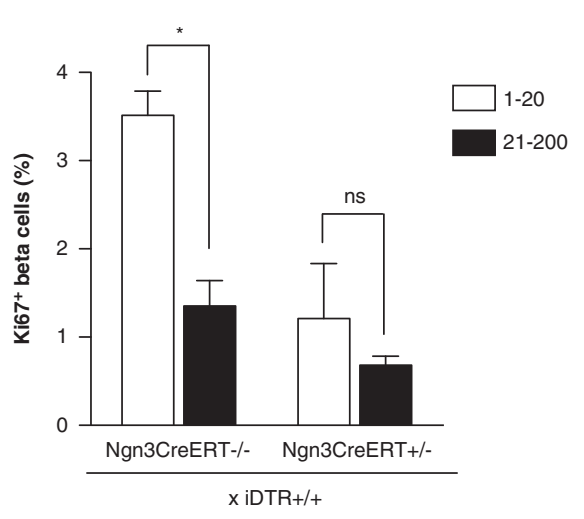

g

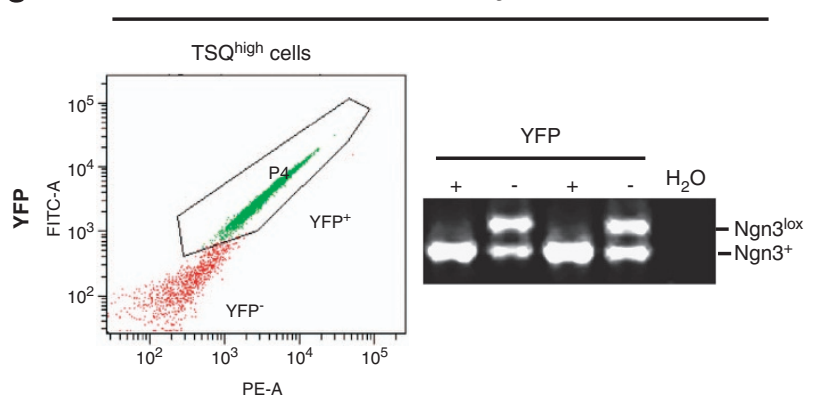

b

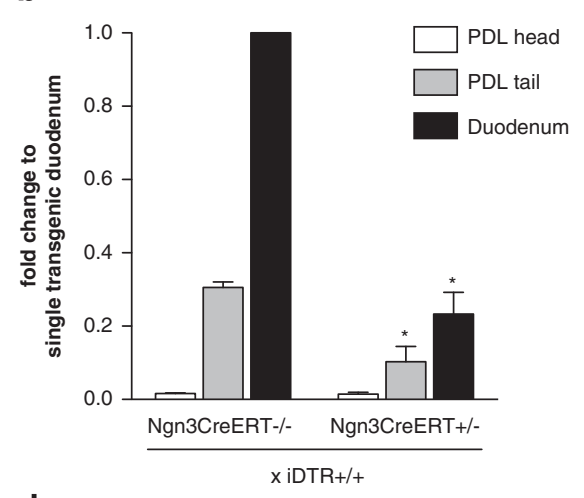

a

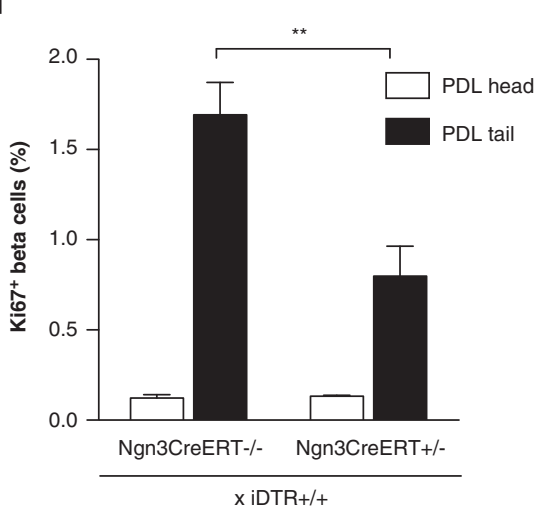

f
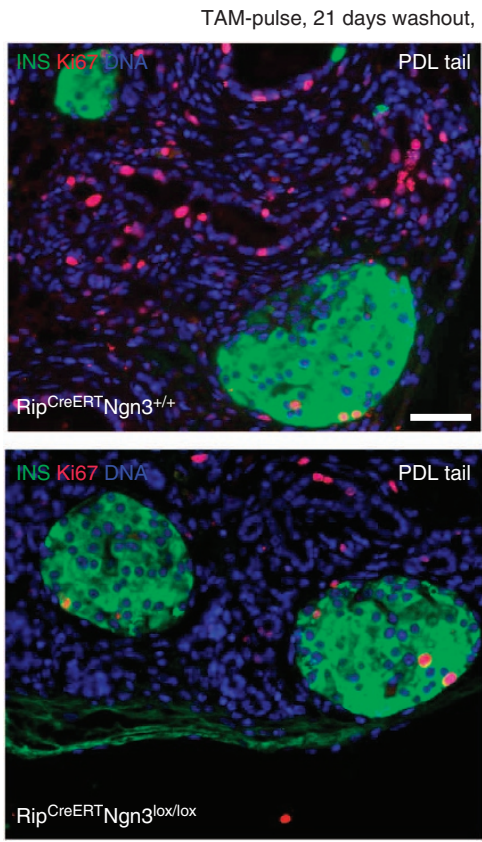
To address whether the expression of Ngn3 in pre-existing $\beta$ cells have a role in $\beta$ cell expansion following PDL, the Ngn3 gene was conditionally inactivated in mature $\beta$ cells of RIP $^{\text {CreERT}}$;Ngn3 ${ }^{\text {lox/lox }}$ mice ${ }^{1,19}$ before PDL surgery. Fiveweek-old mice were TAM-injected followed by a washout period, and PDL surgery was performed at week 8 of age. At day 14 postsurgery, the $\beta$ cell proliferation rate in PDL tail of pancreas in RIP CreERT; Ngn3 $^{\text {lox/lox }}$ mice was not different from that in RIP CreERT $; \mathrm{Ngn}^{+{ }^{++}}$mice (Figure 6f). The efficiency of Ngn3 inactivation in $\beta$ cells, was evaluated in RIP $^{\text {CreERT }}$;R26 ${ }^{\text {YFP }}$;Ngn3 ${ }^{+/ \text {lox }}$ mice that had received TAM as before. After islet isolation and dissociation, islet cells were sorted on basis of TSQ (TSQ ${ }^{\text {high }}$ marks endocrine cells ${ }^{6}$ ) and YFP fluorescence, which showed that $79 \pm 1 \%(n=4)$ of $\mathrm{TSQ}^{\text {high }}$ islet cells were also $\mathrm{YFP}^{+}$, representing $\beta$ cells with Cre activation. Moreover, amplification of DNA extracted from $\mathrm{YFP}^{+} \beta$ cells using $\mathrm{Ngn}^{\text {lox }}{ }^{-}$specific primers revealed that these cells had completely lost their $\mathrm{Ngn}^{\text {lox }}$ allele in contrast to the $\mathrm{YFP}^{-}$islet cells (Figure $6 \mathrm{~g}$ ). Together, the data suggest that deletion of $\mathrm{Ngn} 3$ in pre-existing $\beta$ cells occurred very efficiently, and that Ngn3 in non- $\beta$ and newly formed $\beta$ cells rather than in pre-existing $\beta$ cells was required for $\beta$ cell proliferation and expansion observed in PDL pancreas.

\section{Discussion}

Our previous findings indicated that upon PDL surgery $\beta$ cells expand and $\mathrm{Ngn}^{+}{ }^{+}$endocrine progenitors are activated. ${ }^{6}$ In the present study, we examined relative contributions of neogenesis and proliferation to the expansion of $\beta$ cells. For evaluation of the impact by proliferation of pre-existing $\beta$ cells, three parameters were determined: $\beta$ cell expansion, proliferation rates, and the mode of $\beta$ cell replication. Total $\beta$ cell volume doubled and $\beta$ cells proliferated more in PDL tail pancreas without restriction to re-engage in cycling. Modeling $\beta$ cell proliferation according to these parameters suggests that $86 \%$ of $\beta$ cells in PDL tail pancreas at 14 days postsurgery derive from pre-existing ones. Dilution of permanently labeled pre-existing $\beta$ cells ${ }^{1}$ indicated that $14.6 \%$ of the total $\beta$ cell population derived from non- $\beta$ cells. PDL increased the total number of islets and in particular the number of small islets where $42 \%$ of $\beta$ cells derived from a non- $\beta$ cell origin and the $\beta$ cell cycling activity was high. The small islets can give rise to larger ones within 14 days. The majority of small clusters were composed entirely of dividing $\beta$ cells and there was evidence for large clusters of $>20 \beta$ cells on cross-section that consisted nearly entirely of new $\beta$ cells, while no such islets were found in the unligated part of PDL pancreas. Taken together, our findings show that both neoformation and proliferation of $\beta$ cells contribute to the $\beta$ cell expansion in adult PDL pancreas. We confirm previous findings ${ }^{4}$ that in adult normal pancreas $\beta$ cells in different islets appear to have an equal potential for growth but show that this is not the case in PDL pancreas where small islets are foci for $\beta$ cell (re)replication and neogenesis. The possibility to trigger the formation of islets with replication-prone $\beta$ cells opens a new perspective for regenerative strategies.

Permanent genetic tracing of cells that activated Ngn3 gene expression detected up to $40 \%$ of label $^{+} \beta$ cells in small clusters in PDL. Similar fractions of newly formed label ${ }^{-} \beta$ cells were observed by $\beta$ cell tracing in PDL pancreas suggesting that the $\mathrm{Ngn}^{+}$cells were newly formed $\beta$ cells. Although Ngn3 expression has also been reported in mature $\beta$ cells of normal pancreas, ${ }^{19}$ we found only few label ${ }^{+} \beta$ cells in Sham tail and PDL head pancreas of $\mathrm{Ngn}^{+}$cell tracer mice. Moreover, conditional ablation of $\mathrm{Ngn}^{+}$cells had no effect on the insulin content or $\beta$ cell proliferation in PDL head or Sham tail pancreas, suggesting either no influence of $\mathrm{Ngn}^{+}$ $\beta$ cells on these parameters or a too low expression level of Ngn3 in $\beta$ cells to cause Cre-induced recombination. In contrast, DT-ablation of part of the $\mathrm{Ngn}^{+}$cells in PDL tail reduced both insulin content and $\beta$ cell proliferation. This corroborates our previous finding that knockdown of Ngn3 in PDL pancreas reduces $\beta$ cell proliferation and mass expansion. ${ }^{6}$ Thus, unlike in adult normal pancreas, $\beta$ cell expansion in PDL depends on $\mathrm{Ngn}^{+}$cells. Inactivation of the Ngn3 gene in pre-existing $\beta$ cells does not affect $\beta$ cell proliferation in $\mathrm{PDL}$ tail pancreas suggesting that $\mathrm{Ngn}^{+}{ }^{+}$non- $\beta$ cells or newly formed $\beta$ cells are important for stimulating proliferation as the main mechanism of $\beta$ cell expansion in PDL pancreas. We cannot presently exclude that $\beta$ cells under these conditions are more stressed than in normal conditions, which may enhance $\beta$ cell expression of $\mathrm{Ngn}^{23}$ and dedifferentiation to progenitor-like $\mathrm{Ngn}^{+}{ }^{+}$cells. $^{24}$ We have not observed increased activation of caspase- 3 in PDL $\beta$ cells ( ${ }^{6}$ and unpublished results), and $\beta$ cells isolated from PDL pancreas did not show decreased Foxo1, Ins1 or Ins2 mRNA expression (unpublished data), which seems to argue against dedifferentiation under stress. Nevertheless, this requires more investigation. As only a small proportion of all $\beta$ cells derived from $\mathrm{Ngn}^{+}$cells but $53 \%$ of $\beta$ cell proliferation was prevented by ablation of the $\mathrm{Ngn}^{+}$cells, our data suggest

Figure $6 \mathrm{Ngn}^{+}$cells are required while $\mathrm{Ngn} 3$ in pre-existing $\beta$ cells is dispensable for the $\beta$ cell proliferation in PDL pancreas. (a) Description of the transgenic mouse model and strategy used for selective ablation of $\mathrm{Ngn}^{+}$cells by DT. Tamoxifen injection in bigenic Ngn3Cre ${ }^{\mathrm{ERT}-l+} ;{\mathrm{R} 26^{\mathrm{iDTR}}+l+}$ mice results in permanent heritable expression of the DTR gene in $\mathrm{Ngn}^{+}{ }^{+}$cells and cells derived thereof. Eight-week-old bigenic mice and monogenic Ngn3Cre ${ }^{\text {ERT }-I-}$;R2 $6^{\text {iDTR }+/+}$ littermates underwent PDL surgery, s.c. TAM administration ( ${ }^{*}$ TAM, 4 mg/injection), and i.v. DT (\# daily injections, 125 ng/injection). (b) Ngn3 mRNA expression measured by qRT-PCR in duodenum, and PDL head and tail pancreas of mono- $(n=3)$ or bigenic mice $\left(n=4 ;{ }^{*} P<0.05\right.$ versus the monogenic tissue). Data were normalized to cyclophilin $A$ mRNA and expressed relative to the Ngn3 level in monogenic duodenum. (c) Total insulin content $(\mu \mathrm{g})$ of PDL head and tail pancreas of mono- or bigenic mice $\left(n=3\right.$, $\left.{ }^{\star \star} P<0.01\right)$. (d) Percentage of $\mathrm{Ki}^{+} \beta$ cells in PDL head and tail pancreas of mono- $(n=3)$ or bigenic $(n=4)$ mice $\left({ }^{\star \star} P<0.02\right)$. (e) Percentage of Ki67 ${ }^{+} \beta$ cells in small $(1-20)$ or large $(21-200)$ cell clusters of PDL tail ( $n=3-4,{ }^{*} P<0.05$, ns: $P>0.05$ by two-way ANOVA). Data are expressed as the mean \pm S.E.M. See also Supplementary Figure S8. (f) Following TAM injection and wash out, RIPCreERT;Ngn3 ${ }^{+1+}$ and RIPCreERT;Ngn3 ${ }^{\text {lox/lox }}$ mice underwent PDL surgery. Immunofluorescence staining for Ki67 and insulin in PDL tail tissues is shown. $\beta$ cell proliferation was quantified and expressed as the mean \pm S.E.M. ( $n=6$, ns: $P>0.05$; a total of $30250 \beta$ cells were evaluated). Scale bar represents $50 \mu$ m. (g) RIP $^{\text {CreERT; }}{ }_{\text {R26 }}^{\text {YFP }}$;Ngn3 ${ }^{+/ \text {lox }}$ mice were treated with TAM as in (f). Islets were isolated and dissociated to sort the islet cells on the basis of TSQ (Dapi, not shown) and YFP fluorescence (FITC). The window (left panel) comprises all the TSQ ${ }^{\text {high }}$ (endocrine) cells. The gating indicates YFP ${ }^{+} \beta$ cells (green dots). YFP $^{-}$islet cells (red dots) were also collected. YFP ${ }^{-}$islet cells had a wild-type $\left(\mathrm{Ngn}^{+}\right)$and a floxed $\left(\mathrm{Ngn}^{\mathrm{lox}}\right)$ allele, whereas $\mathrm{YFP}^{+} \beta$ cells had lost the Ngn3 ${ }^{\text {lox }}$ allele. PCR results for two separate isolations are shown (right panel) 
non cell autonomous stimulation of $\beta$ cell proliferation by $\mathrm{Ngn}^{+}$cells in PDL. Our finding of newly-formed but also preexisting $\beta$ cells with high cycling activity within small clusters suggests that the microenvironment of small islets in PDL have a role in enhanced recruitment of $\beta$ cells into cycling.

The inconsistent outcome of PDL in terms of $\beta$-cell neogenesis ${ }^{12-14}$ in recent studies may be explained by differences in activation of Ngn3 gene expression. Our data suggest $\beta$-cell neogenesis to correlate with Ngn3 gene expression following PDL, arguing in favor of a threshold below which reprogramming will not be stimulated -a principle that has been described before ${ }^{25}$ - and providing us with a way to screen for conditions and drugs favoring this process. In view of our present data, relatively poor activation of Ngn3 gene expression in PDL pancreas as reported by some $^{12,13}$ is an unfavorable condition for $\beta$-cell neogenesis. On the other hand, our present data on Ngn3 tracing and dilution of pre-existing $\beta$ cells indicate that direct derivation of $\beta$ cells from $\mathrm{Ngn}^{+}$non- $\beta$ cells in PDL is not as high as initially claimed in Xu et al. ${ }^{6}$, even in PDL pancreas with strong Ngn3 gene induction.

We do find, however, that $\mathrm{Ngn}^{+}{ }^{+}$non- $\beta$ cells are key to the in vivo expansion of $\beta$ cells and generation of replication-prone $\beta$ cells in injured adult pancreas. A mechanistic role for $\mathrm{Ngn}^{+}$ cell activation in $\beta$ cell formation in PDL is supported by the correlation between Ngn3-transcript levels and the preponderance of $\mathrm{Ngn}^{+}$cells on the one hand and the finding that $\beta$ cell proliferation depends on $\mathrm{Ngn}^{+}$cells on the other. Our findings provide a platform for characterization of the signals that control neogenesis and $\beta$ cell proliferation in the adult pancreas and may be drug targets for regenerative treatment of diabetes.

\section{Materials and Methods \\ Mouse manipulation. All mice experiments were performed according to the guidelines of our institutional 'Ethical Committee for Animal Experiments' and national guidelines and regulations. Pancreatic duct ligation or Sham operation were performed as described. ${ }^{6,10}$}

Cell tracing. Mice were continuously labeled by administering CldU, IdU, in drinking water bottles at $1 \mathrm{mg} / \mathrm{ml}^{3}$. CldU (C6891) and IdU (347580) were obtained from Sigma Aldrich (Diegem, Belgium).

Tamoxifen (Sigma, T5648) was dissolved at $10 \mathrm{mg} / \mathrm{ml}$ in corn oil (Sigma, C8267). For PDL studies in adult mice, a total of $20 \mathrm{mg}$ of tamoxifen (TAM) was given s.c. in five doses (each $4 \mathrm{mg}$ ) over a 2 -week period. In Ngn3 ${ }^{\text {CreERT }} ; R_{2} 6^{\text {DTR }}$ mice, diphtheria toxin was given (three tail vein injections of $125 \mathrm{ng}$ each) during the last 3 days of the post-PDL period.

$\beta$ cell volume and insulin content. The measurement of $\beta$ cell volume $\left(\mathrm{mm}^{3}\right)$ in PDL or Sham tail pancreas was performed as described previously. ${ }^{6}$ Analysis of each organ was based on a large number of $4 \mu \mathrm{m}$-sections equally spaced and spanning the whole tissue, together representing $10 \%$ of the total volume. Measurement of pancreas insulin content was done as described ${ }^{26}$ as well as OPT 3D analysis. ${ }^{16}$

Immunolocalization and histochemical procedures. Samples for immunohistochemistry were fixed in $4 \%$ formaldehyde overnight and embedded in paraffin. Paraffin sections $(4-5 \mu \mathrm{m})$ were incubated with antisera specific for insulin (1/3000, guinea pig, generated at the Diabetes Research Center, Brussels, Belgium), glucagon (1/3000, rabbit), Nkx6.1 (1/2000, rabbit, Beta cell biology consortium, Nashville, TN, USA), Ki67 (1/1000, rabbit, Novocastra, Leica Microsystems, Diegem, Belgium), CK19 (1/100, rat, DSHB, University of lowa, lowa, USA), GFP (1/100, goat, Abcam, Cambridge, UK), anti $\beta$-galactosidase (bGal) (1/500, rabbit, Invitrogen, Life Technologies, Ghent, Belgium), anti-BrdU antisera (IdU) (1/100, mouse, BD Biosciences, Erembodegem, Belgium) and anti-CldU antisera (1/250, rat, Gentaur molecular products, Kampenhout, Belgium). Antigen retrieval was required for recognition of thymidine analogs (microwaved in $0.01 \mathrm{~m}$ sodium citrate, permeabilized with $1 \%$ Triton, incubated in $1.5 \mathrm{~N} \mathrm{HCL}$ ) and CK19 (citrate buffer). Secondary antibodies for detection of guinea pig, rabbit, goat or rat antibodies were labeled by fluorescence (Cy3, Cy2, Cy5 or AMCA) (Jackson Immuno-Research Labs, Suffolk, UK). Nuclei were labeled by Hoechst 33342 (4 mg/ml, Sigma).

Image analysis. Images were acquired with a normal (Olympus, Aartselaar, Belgium, BX61 with Hamamatsu C10600 ORKA-R ${ }^{2}$ camera) or confocal scanning (Leica, Aartselaar, Belgium, TCS-SP and Zeiss (Carl Zeiss, Zaventem, Belgium) LSM710 NLO) microscopy. CldU-, IdU- or CldU- and IdU-positive or Ki67/bGal/YFPexpressing cells were counted separately and localization within insulin ${ }^{+}(\beta)$ cells was checked individually. At least $3000 \beta$ cells per sample were counted unless stated otherwise. Images were analyzed using Smartcapture 3 (version 3.0.8, Cambridge, UK), NIH ImageJ (U.S. National Institutes of Health, Bethesda, MD, USA) and Photoshop CS (version 1.3.1, Adobe, San Jose, CA, USA). Confocal images were processed using Improvision Volocity LE (Perkin Elmer, Zaventem, Belgium) and Zeiss Zen software (Carl Zeiss).

RNA and DNA analysis. Total RNA was isolated from tissue (RNeasy, QIAGEN, Venlo, Netherlands). Only RNA with RNA Integrity Number R $\geq 7$ (2100 BioAnalyzer, Agilent, Diegem, Belgium) was further analyzed. cDNA synthesis and RT-PCR were done using mouse-specific primers and probes recognizing Ngn3 and cyclophilin A (Mm02342429) with TaqMan Universal PCR master mix on an ABI Prism 7700 Sequence Detector, and data were analyzed using the Sequence Detection Systems Software, version 1.9.1 (all Applied Biosystems, Life Technologies). The following sequences were used for analysis of Ngn3: $5^{\prime}-G T$ CGGGAGAACTAGGATGGC-3' (forward primer), 5'GGAGCAGTCCCTAGGTA TG-3' (reverse primer) and $5^{\prime}$-CGGAGCCTCGGACCACGAA-3'go (probe). Quantitative PCR reactions were then performed with CDNA corresponding to $20 \mathrm{ng}$ RNA as described. ${ }^{6}$ Data were normalized to cyclophilin A, and expressed relative to values obtained for duodenum samples, which were the internal reference for $\mathrm{Ngn} 3$ expression.

Pancreatic islets were isolated and dissociated, and islet cells sorted by FACS, as previously described. ${ }^{6,26}$ Islet cell DNA was extracted using the DNeasy blood and tissue 250 kit (Qiagen; cat.no.69506). Screening for $\mathrm{Ngn}^{\mathrm{lox}}$ and $\mathrm{Ngn}^{+}$alleles in islet cells was by classical PCR on genomic DNA using primers $722+723$, as described. ${ }^{27}$ These primers do not amplify the $\mathrm{Ngn}^{-}$allele that is produced by Cre-mediated deletion of $\mathrm{Ngn}^{\mathrm{lox}}$.

Statistics. Data are expressed as mean \pm S.E.M. of at least three independent experiments. Differences between data were analyzed by unpaired two-tailed student's t-test, one-way ANOVA, or two-way ANOVA with Bonferroni post hoctest, and were considered statistically significant when $P<0.05$.

\section{Conflict of Interest}

The authors declare no conflict of interest.

Acknowledgements. Special thanks are to Ann Demarré, Veerle Laurysens, Jan De Jonge and Erik Quartier for technical assistance. Financial support was from the VUB Research Council (HH, MVDC), the Institute for the Promotion of Innovation by Science and Technology in Flanders (IWT) (HH, VC), the Beta Cell Biology Consortium $(\mathrm{HH})$, the Chinese Scholarship Council (YY), the Fund for Scientific Research Flanders (HH, SDG, and LB).

\section{Author contributions}

MVDC, GL, LB, YC, ODM, AW, YD, JNJ, HH: study concept and design; MVDC, GL, LB, YC, YY, VC, SDG, ME, CS, UA, JAR, HH: acquisition, analysis or interpretation of data.

1. Dor Y, Brown J, Martinez OI, Melton DA. Adult pancreatic beta-cells are formed by selfduplication rather than stem-cell differentiation. Nature 2004; 429: 41-46.

2. Nir $\mathrm{T}$, Melton DA, Dor $Y$. Recovery from diabetes in mice by beta cell regeneration. J Clin Invest 2007; 117: 2553-2561.

3. Teta M, Rankin MM, Long SY, Stein GM, Kushner JA. Growth and regeneration of adult beta cells does not involve specialized progenitors. Dev Cell 2007; 12: 817-826. 
4. Brennand $\mathrm{K}$, Huangfu $\mathrm{D}$, Melton D. All beta cells contribute equally to islet growth and maintenance. PLOS Biol 2007; 5: e163.

5. Salpeter SJ, Klein AM, Huangfu D, Grimsby J, Dor Y. Glucose and aging control the quiescence period that follows pancreatic beta cell replication. Development 2010; 137: 3205-3213.

6. Xu X, D'Hoker J, Stange G, Bonne S, De Leu N, Xiao X et al. Beta cells can be generated from endogenous progenitors in injured adult mouse pancreas. Cell 2008; 132: 197-207.

7. Gradwohl G, Dierich A, LeMeur M, Guillemot F. neurogenin3 is required for the development of the four endocrine cell lineages of the pancreas. Proc Natl Acad Sci USA 2000; 97: 1607-1611.

8. Gu G, Dubauskaite J, Melton DA. Direct evidence for the pancreatic lineage: NGN3 + cells are islet progenitors and are distinct from duct progenitors. Development 2002; 129: 2447-2457.

9. Apelqvist A, Li H, Sommer L, Beatus P, Anderson DJ, Honjo $\mathrm{T}$ et al. Notch signalling controls pancreatic cell differentiation. Nature 1999; 400: 877-881.

10. Wang RN, Kloppel G, Bouwens L. Duct- to islet-cell differentiation and islet growth in the pancreas of duct-ligated adult rats. Diabetologia 1995; 38: 1405-1411.

11. Inada A, Nienaber C, Katsuta H, Fujitani Y, Levine J, Morita R et al. Carbonic anhydrase IIpositive pancreatic cells are progenitors for both endocrine and exocrine pancreas after birth. Proc Natl Acad Sci USA 2008; 105: 19915-19919.

12. Kopp JL, Dubois CL, Schaffer AE, Hao E, Shih HP, Seymour PA et al. Sox9 + ductal cells are multipotent progenitors throughout development but do not produce new endocrine cells in the normal or injured adult pancreas. Development 2011; 138: 653-665.

13. Solar M, Cardalda C, Houbracken I, Martin M, Maestro MA, De Medts N et al. Pancreatic exocrine duct cells give rise to insulin-producing beta cells during embryogenesis but not after birth. Dev Cell 2009; 17: 849-860.

14. Furuyama K, Kawaguchi $\mathrm{Y}$, Akiyama $\mathrm{H}$, Horiguchi M, Kodama $\mathrm{S}$, Kuhara $\mathrm{T}$ et al. Continuous cell supply from a Sox9-expressing progenitor zone in adult liver, exocrine pancreas and intestine. Nat Genet 2011; 43: 34-41.

15. Kopinke D, Brailsford M, Shea JE, Leavitt R, Scaife CL, Murtaugh LC. Lineage tracing reveals the dynamic contribution of Hes $1+$ cells to the developing and adult pancreas. Development 2011; 138: 431-441.

16. Alanentalo T, Asayesh A, Morrison H, Loren CE, Holmberg D, Sharpe J et al. Tomographic molecular imaging and 3D quantification within adult mouse organs. Nat Methods 2007; 4: 31-33.

17. Hornblad A, Cheddad A, Ahlgren U. An improved protocol for optical projection tomography imaging reveals lobular heterogeneities in pancreatic islet and beta-cell mass distribution. Islets 2011; 3: 204-208.
18. Cheddad A, Svensson C, Sharpe J, Georgsson F, Ahlgren U. Image processing assisted algorithms for optical projection tomography. IEEE Trans Med Imaging 2012; 31: 1-15.

19. Wang S, Jensen JN, Seymour PA, Hsu W, Dor Y, Sander M et al. Sustained Neurog3 expression in hormone-expressing islet cells is required for endocrine maturation and function. Proc Natl Acad Sci USA 2009; 106: 9715-9720.

20. Srinivas S, Watanabe T, Lin CS, William CM, Tanabe $Y$, Jessell TM et al. Cre reporter strains produced by targeted insertion of EYFP and ECFP into the ROSA26 locus. BMC Dev Biol 2001; 1 : 4.

21. Soriano P. Generalized lacZ expression with the ROSA26 Cre reporter strain. Nat Genet 1999; 21: 70-71.

22. Buch T, Heppner FL, Tertilt C, Heinen TJ, Kremer M, Wunderlich FT et al. A Cre-inducible diphtheria toxin receptor mediates cell lineage ablation after toxin administration. Nat Methods 2005; 2: 419-426.

23. Dror V, Nguyen V, Walia P, Kalynyak TB, Hill JA, Johnson JD. Notch signalling suppresses apoptosis in adult human and mouse pancreatic islet cells. Diabetologia 2007; 50: 2504-2515.

24. Talchai C, Xuan S, Lin HV, Sussel L, Accili D. Pancreatic beta cell dedifferentiation as a mechanism of diabetic beta cell failure. Cell 2012; 150: 1223-1234.

25. Beaudry JB, Pierreux CE, Hayhurst GP, Plumb-Rudewiez N, Weiss MC, Rousseau GG et al. Threshold levels of hepatocyte nuclear factor 6 (HNF-6) acting in synergy with HNF-4 and PGC-1alpha are required for time-specific gene expression during liver development. Mol Cell Biol 2006; 26: 6037-6046.

26. Grouwels G, Cai Y, Hoebeke I, Leuckx G, Heremans Y, Ziebold U et al. Ectopic expression of E2F1 stimulates beta-cell proliferation and function. Diabetes 2010; 59 : 1435-1444.

27. Wang S, Hecksher-Sorensen J, Xu Y, Zhao A, Dor Y, Rosenberg L et al. Myt1 and Ngn3 form a feed-forward expression loop to promote endocrine islet cell differentiation. Dev Biol 2008; 317: 531-540.

(c) (i) $(9)$ Cell Death and Disease is an open-access journal published by Nature Publishing Group. This work is licensed under the Creative Commons Attribution-NonCommercial-No Derivative Works 3.0 Unported License. To view a copy of this license, visit http://creativecommons.org/licenses/by-nc-nd/3.0/

Supplementary Information accompanies this paper on Cell Death and Disease website (http://www.nature.com/cddis) 